\title{
Compromise Hypersphere for Multi-Criteria Dynamic Programming
}

\author{
Sebastian Sitarz \\ Institute of mathematics, University of Silesia, Poland \\ Email: ssitarz@math.us.edu.pl
}

\begin{abstract}
The paper considers multi-criteria dynamic decision process. We focus on the efficient realizations of the dynamic process which are characterized by nondominated values of the multi-period criteria function. The aim of the paper is to use the compromise hypersphere method to rank the efficient realizations. The presented method allows us to take into account the risk aversion of the decision maker. Moreover, we apply the presented theory in the market model taken from microeconomic theory.
\end{abstract}

Index Terms - Dynamic programming, multi-criteria decision making, compromise hypersphere.

\section{INTRODUCTION}

The paper presents a usage of compromise hypersphere in multi-criteria dynamic programming. The form of dynamic programming model is taken from the works by Sitarz [1] and [2]. The most recent contributions to dynamic programming in the view of the proposed approach are as follows. Bazgan et al. [3] present the approach of ordered structures in dynamic programming. Sitarz [4] shows a usage of dynamic programming into multiple knapsack problem. In [5] the stochastic dynamic programming on compact state spaces is discussed. Whereas the idea of compromise hypersphere comes from the work by Gass and Roy [6]. The source of the compromise hypersphere is the compromise programming presented in [7] and [8]. By using the presented method, we obtain the decision analysis tool in multi-criteria dynamic problems. The method consists of three steps. In step 1 we determine a set of efficient realizations in discrete dynamic programming model by using the forward algorithm. In step 2 we find the compromise hypersphere, which means a kind of compromise between the values of efficient realizations. In step 3 we build the ranking of efficient realization by using the compromise hypersphere. Moreover, by using the presented method we are able to take into account the risk aversion of the decision maker by choosing the parameter of the method. The general form of the presented model allows us to use it in many problems, particularly we apply the method in the market model.
The paper consists of the following sections. Section II presents discrete dynamic programming model with forward algorithm for finding the efficient realizations. Section III introduces compromise hypersphere method with the proposition of risk aversion measure. Section IV shows an application of the proposed method in the market model. The paper is summarized in the final section $\mathrm{V}$.

\section{DYNAMIC DECISION PROCESS}

Discrete dynamic process is considered. The notation of this process is described in Table 1 .

\section{A. Period criteria functions}

Let $\mathrm{P}$ stand for the process. The period criteria function in the period $\mathrm{t}(\mathrm{t}=1, \ldots \mathrm{T})$ is the function:

$$
\mathrm{f}_{\mathrm{t}}: \mathrm{R}_{\mathrm{t}} \rightarrow \mathbb{R}^{\mathrm{k}}
$$

where $\mathbb{R}^{\mathrm{n}}$ denotes the $\mathrm{n}$-dimensional vector of real numbers. Next, we assume the following simplification of the notation:

$$
f_{t}\left(s_{t}, s_{t+1}\right)=f_{t}\left(\left(s_{t}, s_{t+1}\right)\right)
$$

Below, we present the definitions of the multi-period criteria function by using the binary operator $\circ$, which links the period valeus.

- Partial backward criteria function $\mathrm{F}_{\mathrm{t}}^{\leftarrow}: \mathrm{R}_{\mathrm{t}}^{\leftarrow}\left(\mathrm{S}_{\mathrm{t}}\right) \rightarrow \mathbb{R}^{\mathrm{k}}$ :

$$
\mathrm{F}_{\mathrm{t}}^{\leftarrow}=\mathrm{f}_{\mathrm{t}} \circ\left(\mathrm{f}_{\mathrm{t}-1} \circ\left(\ldots\left(\mathrm{f}_{\mathrm{T}-1} \circ \mathrm{f}_{\mathrm{T}}\right) \ldots\right)\right)
$$

- Partial forward criteria function $\mathrm{F}_{\mathrm{t}} \rightarrow \mathrm{R}_{\mathrm{t}} \rightarrow\left(\mathrm{S}_{\mathrm{t}}\right) \rightarrow \mathbb{R}^{\mathrm{k}}$ :

$$
F_{t} \rightarrow\left(\left(\ldots\left(f_{1} \circ f_{2}\right) \ldots\right) \circ f_{t-2}\right) \circ f_{t-1}
$$

- Multi-period criteria function $\mathrm{F}: \mathrm{R} \rightarrow \mathbb{R}^{\mathrm{k}}$ :

$$
F=\left(\left(\ldots\left(f_{1} \circ f_{2}\right) \circ \ldots\right) \circ f_{T-1}\right) \circ f_{T}
$$


Table 1. Notation of dynamic process.

\begin{tabular}{|c|c|c|}
\hline Symbol & Meaning & Elements description \\
\hline $\mathrm{T}$ & The number of stages & $\mathrm{t} \in\{1, \ldots, \mathrm{T}\}$ \\
\hline $\mathrm{S}_{\mathrm{t}}$ & $\begin{array}{c}\text { The set of feasible states } \\
\text { at the beginning of the } \\
\text { stage } t\end{array}$ & $\mathrm{~S}_{\mathrm{t}}$ \\
\hline $\mathrm{D}_{\mathrm{t}}\left(\mathrm{s}_{\mathrm{t}}\right)$ & $\begin{array}{c}\text { The set of feasible } \\
\text { decisions at the beginning } \\
\text { of the stage } t \text {, in the state } \\
s_{t}\end{array}$ & $\mathrm{~d}_{\mathrm{t}}\left(\mathrm{s}_{\mathrm{t}}\right)$ \\
\hline $\mathrm{R}$ & $\begin{array}{c}\text { Realizations of the } \\
\text { process- } \\
\text { sequence of the } \\
\text { succeeding states }\end{array}$ & $\mathrm{r}=\left(\mathrm{s}_{1}, \mathrm{~s}_{2}, . ., \mathrm{s}_{\mathrm{T}}, \mathrm{s}_{\mathrm{T}+1}\right)$ \\
\hline $\mathrm{R}_{\mathrm{t}}$ & $\begin{array}{l}\text { The set of stage } \\
\text { realizations at the } \\
\text { beginning of the stage } t\end{array}$ & $\mathrm{r}_{\mathrm{t}}=\left(\mathrm{s}_{\mathrm{t}}, \mathrm{s}_{\mathrm{t}+1}\right)$ \\
\hline $\mathrm{R}_{\mathrm{t}}^{\leftarrow}\left(\mathrm{s}_{\mathrm{t}}\right)$ & $\begin{array}{l}\text { The set of partial } \\
\text { realizations of the process } \\
\text { beginning at the point } t \\
\text { and the state } s_{t}\end{array}$ & $\mathrm{r}_{\mathrm{t}}^{\leftarrow}\left(\mathrm{s}_{\mathrm{t}}\right)=\left(\mathrm{s}_{\mathrm{t}}, \ldots, \mathrm{s}_{\mathrm{T}+1}\right)$ \\
\hline $\mathrm{R}_{\mathrm{t}} \rightarrow\left(\mathrm{s}_{\mathrm{t}}\right)$ & $\begin{array}{l}\text { The set of partial } \\
\text { realizations of the process } \\
\text { ending at the point } t \text { in the } \\
\text { state } s_{t}\end{array}$ & $\mathrm{r}_{\mathrm{t}} \rightarrow\left(\mathrm{s}_{\mathrm{t}}\right)=\left(\mathrm{s}_{1}, \ldots, \mathrm{s}_{\mathrm{t}}\right)$ \\
\hline $\mathrm{R}_{\mathrm{t}} \leftarrow\left(\mathrm{S}_{\mathrm{t}}\right)$ & $\begin{array}{l}\text { The set of partial } \\
\text { realizations beginning at } \\
\text { the point } \mathrm{t}\end{array}$ & $\mathrm{r}_{\mathrm{t}}^{\leftarrow}\left(\mathrm{s}_{\mathrm{t}}\right): \mathrm{s}_{\mathrm{t}} \in \mathrm{S}_{\mathrm{t}}$ \\
\hline $\mathrm{R}_{\mathrm{t}} \rightarrow\left(\mathrm{S}_{\mathrm{t}}\right)$ & $\begin{array}{l}\text { The set of partial } \\
\text { realizations ending at the } \\
\text { point } t\end{array}$ & $\mathrm{r}_{\mathrm{t}}^{\leftarrow}\left(\mathrm{s}_{\mathrm{t}}\right): \quad \mathrm{s}_{\mathrm{t}} \in \mathrm{S}_{\mathrm{t}}$ \\
\hline $\mathrm{P}$ & $\begin{array}{l}\text { The process in which T, } \\
S_{t}, D_{t}\left(s_{t}\right) \text { were defined }\end{array}$ & \\
\hline
\end{tabular}

Next, we assume the notation

$$
\begin{aligned}
\mathrm{F}_{\mathrm{t}}^{\leftarrow}\left(\mathrm{R}_{\mathrm{t}}{ }^{\leftarrow}\left(\mathrm{S}_{\mathrm{t}}\right)\right) & =\left\{\mathrm{F}_{\mathrm{t}}^{\leftarrow}\left(\mathrm{R}_{\mathrm{t}}^{\leftarrow}\left(\mathrm{s}_{\mathrm{t}}\right)\right): \mathrm{s}_{\mathrm{t}} \in \mathrm{S}_{\mathrm{t}}\right\} \\
\mathrm{F}_{\mathrm{t}} \rightarrow\left(\mathrm{R}_{\mathrm{t}}{ }^{\leftarrow}\left(\mathrm{S}_{\mathrm{t}}\right)\right) & =\left\{\mathrm{F}_{\mathrm{t}} \rightarrow\left(\mathrm{R}_{\mathrm{t}} \rightarrow\left(\mathrm{s}_{\mathrm{t}}\right)\right): \mathrm{s}_{\mathrm{t}} \in \mathrm{S}_{\mathrm{t}}\right\} \\
\mathrm{F}(\mathrm{R}) & =\{\mathrm{F}(\mathrm{r}): \mathrm{r} \in \mathrm{R}\}
\end{aligned}
$$

\section{B. Efficient realizations}

Non-dominated vectors of the set $A \subset \mathbb{R}^{\mathrm{k}}$ denoted as $\mathrm{ND}(\mathrm{A})$ are described in the following way:

$$
\mathrm{ND}(\mathrm{A})=\left\{\mathrm{a} \in \mathrm{A}: \forall_{\mathrm{x} \in \mathrm{A}} \mathrm{a} \leq \mathrm{x} \Rightarrow \mathrm{x}=\mathrm{a}\right\}
$$

The realization $r \in R$ is called the efficient realization when

$$
\mathrm{F}(\mathrm{r}) \in \mathrm{ND}\{\mathrm{F}(\mathrm{R})\}
$$

The set of all efficient realizations is denoted as $\operatorname{EFF}(\mathrm{R})$.

\section{Forward Algorithm}

The above terms launch a problem of finding all efficient realizations. The detailed description of the methods used for such problems may be found in the work by Trzaskalik and Sitarz [9]. Moreover, the work by Sitarz [10] presents the heuristic methods for such problems. Below, we present the forward algorithm from the work of Sitarz [11]:

Step 1. Find

$$
\mathrm{ND}\left\{\mathrm{f}_{1}\left(\mathrm{R}_{2} \rightarrow\left(\mathrm{s}_{2}\right)\right\} \text {, for all states } \mathrm{s}_{2} \in \mathrm{S}_{2}\right. \text {. }
$$

Step 2. Find

$$
\mathrm{ND}\left\{\mathrm{F}_{2} \rightarrow\left(\mathrm{R}_{3} \rightarrow\left(\mathrm{s}_{3}\right)\right\} \text {, for all states } \mathrm{s}_{3} \in \mathrm{S}_{3}\right. \text {. }
$$

using the values found in step 1

$$
\begin{aligned}
& \mathrm{ND}\left\{\mathrm{F}_{2} \rightarrow\left(\mathrm{R}_{3} \rightarrow\left(\mathrm{s}_{3}\right)\right\}=\mathrm{ND}\left\{\mathrm{f}_{2}\left(\mathrm{~s}_{2}, \mathrm{~s}_{3}\right) \circ \mathrm{ND}\left(\mathrm{f}_{1}\left(\mathrm{R}_{2} \rightarrow\left(\mathrm{s}_{2}\right)\right)\right)\right. \text { : }\right. \\
& \left.\mathrm{s}_{3} \in \mathrm{D}_{2}\left(\mathrm{~s}_{2}\right)\right\}
\end{aligned}
$$

Step $\mathbf{t}$, for $\mathbf{t}=3, \ldots, \mathbf{T}$. Analogically to step 2 , find

$$
\mathrm{ND}\left\{\mathrm{F}_{\mathrm{t}} \rightarrow\left(\mathrm{R}_{\mathrm{t}+1} \rightarrow\left(\mathrm{s}_{\mathrm{t}+1}\right)\right\} \text {, for all states } \mathrm{s}_{\mathrm{t}+1} \in \mathrm{S}_{\mathrm{t}+1}\right. \text {. }
$$

Step $\mathbf{T}+1$. Find $\max \{\mathrm{F}(\mathrm{R})\}$

$\mathrm{ND}\{\mathrm{F}(\mathrm{R})\}=\mathrm{ND}\left\{\mathrm{ND} \mathrm{F} \mathrm{F}_{\mathrm{T}+1} \rightarrow\left(\mathrm{r}_{\mathrm{t}+1} \rightarrow\left(\mathrm{s}_{\mathrm{T}+1}\right)\right): \mathrm{s}_{\mathrm{T}+1} \in \mathrm{S}_{\mathrm{T}+1}\right\}$

At the same time, we get efficient realizations $\operatorname{EFF}(\mathrm{R})$ which relate to the found maximal values.

\section{COMPROMISE HYPERSPHERE METHOD}

The aim of the method is to rank the efficient realizations in discrete dynamic programming model. The main idea of the proposed method comes from the work by Gass and Roy [6]. The method consists of three steps. Step 1 presents an initial problem of decision making - finding a set of efficient realziations. In step 2 we look for a hypersphere which we call a compromise hypersphere. In this case the word compromise means a surface of compromise over the values of nondominated extreme solutions. Thus, we look for the points which are closest to this surface. It means that the point closest to this surface is the best compromise solution. In step 3 we built ranking of points by using distance to the compromise hypersphere. In detail, the method looks as follows:

Step 1. Determine a set of efficient realizations in discrete dynamic programming model by using the forward algorithm presented in subsection II.C. We will denote these efficient realizations as: $r^{1}, r^{2}, \ldots, r^{n}$. 
Step 2. Find a hypersphere with the centre $\mathbf{y}^{0} \in \mathbb{R}^{\mathrm{k}}$ and radius $r_{0} \in \mathbb{R}$ by solving the program

$$
\min _{\mathbf{y}^{0}, r_{0}} l_{q}^{n}\left(\left[r_{0}, \ldots, r_{0}\right],\left[l_{2}^{k}\left(\mathrm{~F}\left(\mathrm{r}^{1}\right), \mathbf{y}^{0}\right), \ldots, l_{2}^{k}\left(\mathrm{~F}\left(\mathrm{r}^{n}\right), \mathbf{y}^{0}\right)\right]\right)
$$

where

$q \in[1, \infty]$ is parameter

$l_{q}^{n}$ is function belonging to the family of metrics $l_{r}^{s}: \mathbb{R}^{s} \times \mathbb{R}^{s} \rightarrow \mathbb{R}$ with the following form:

$$
l_{r}^{s}(\mathbf{a}, \mathbf{b})= \begin{cases}\sqrt[r]{\sum_{i=1}^{s}\left|a_{i}-b_{i}\right|^{r}}, & r \in[1, \infty) \\ \max _{i=1, \ldots, s}\left|a_{i}-b_{i}\right|, & r=\infty\end{cases}
$$

We will denote the optimal solution of (13) as $\overline{\mathbf{y}^{0}}$, $\bar{r}_{0}^{q}$ and the minimal value of the cost function as $\overline{\min }(13)^{q}$. Moreover, wherever it does not cause notion misunderstanding, we will omit index $q$ i.e. $\overline{\mathbf{y}^{0}}, \overline{r_{0}}$ and $\overline{\min }(13)$.

Step 3. Find the ranking of the points $r^{1}, r^{2}, \ldots, r^{n}$ based on the distance from the previously found hypersphere in step 2 , using values

$$
\left|\overline{r_{0}}-l_{2}^{k}\left(\mathrm{~F}\left(\mathrm{r}^{i}\right), \mathbf{y}^{0}\right)\right|
$$

We will particularly look for the point $\mathrm{r}^{i}$ closest to the hypersphere:

$$
\min _{i}\left|\bar{r}_{0}-l_{2}^{k}\left(\mathrm{~F}\left(\mathrm{r}^{i}\right), \mathbf{y}^{0}\right)\right|
$$

We will denote the optimal solution of (16) as $\bar{i}$, the optimal extreme point as $\overline{\mathrm{r}^{i}}$, and the minimal value of the cost function as $\overline{\min }(16)$.

\section{A. Risk aversion measure - the choice of $q$}

The choice of the metric (the value of $q$ ) should go along with some preferences of the decision maker, which is described by Ballestero [12] who concludes his works by sentence: "The greater risk aversion the greater $q$-metric to use. Metric $q=\infty$ corresponds to extremely high risk aversion". Thus the preferences of the decision maker can be incorporated in the presented method by choosing the parameter $q$ - representation of the risk aversion.

By using the above theory, we can formulate the following comments to setting parameter $q$ :

- $q=1$ corresponds to extremely low risk aversion,

- $q=\infty$ corresponds to extremely high risk aversion,
- $q \in(1, \infty)$ corresponds to risk aversion between low and high.

The above scale, $[1, \infty]$, can be hard to use in practice. Thus, we propose to transform interval $[1, \infty]$ to interval $[0,1]$ by a given bijection $f$, for example by $f(q)=$ $(2 / \pi) \cdot \arctan (q-1)$. After using such a transformation $f$, the decision maker gives a value from interval $[0,1]$ to describe his risk aversion in the following way:

- $f(q)=0$ corresponds to extremely low risk aversion,

- $f(q)=1$ corresponds to extremely high risk aversion,

- $f(q) \in(0,1)$ corresponds to risk aversion between low and high.

\section{APPLICATION IN THE MARKET MODEL}

The form of the problem is inspired by the work of Ekeland [13]. We should add that the problem assumes indivisibility of goods available on the market, whereas in the mentioned work, the value of the goods is described by any nonnegative real number.

The presented problem refers to the theory of demand that describes the economic market, in which there is a group of participants (hereafter referred to as consumers). You can purchase a certain amount of goods on the market. Generally, the consumers aim to reach the greatest satisfaction from the purchase of goods. The satisfaction is described with the help of the utility function value. The aim of the problem below is to find such a distribution of goods among the consumers. Below, we present the detailed description of the problem.

$\mathrm{n}$ - the number of goods on the market. Particular goods will be denoted by the letter $i$, that is $i \in\{1, \ldots, n\}$. We assume that the goods are indivisible which means that each commodity appears in a value belonging to the set $\mathbb{N}=\{0,1,2, \ldots\}$.

$\mathrm{m}$ - the number of consumers. Particular consumers will be denoted by the letter $\mathrm{k}$, that is $\mathrm{k} \in\{1, \ldots, \mathrm{m}\}$.

$\Omega_{\mathrm{i}}$ - value of $\mathrm{i}^{\text {th }}$ commodity available on the market, $\Omega_{\mathrm{i}}$ $\in \mathbb{N}$, for $i \in\{1, \ldots, n\}$.

$\Omega=\left(\Omega_{1}, \ldots, \Omega_{\mathrm{n}}\right)-$ joint value of goods available on the market.

$\mathrm{u}_{\mathrm{k}}: \mathbb{N}^{\mathrm{n}} \rightarrow \mathbb{R}$ - utility function of $\mathrm{k}^{\text {th }}$ consumer (describes the preferences of $k^{\text {th }}$ consumer depending on the value of the possessed goods).

Feasible allocations are the vectors

$\mathrm{x}=\left(\mathrm{x}_{1}{ }^{1}, \ldots, \mathrm{x}_{\mathrm{n}}{ }^{1}, \ldots, \mathrm{x}_{1}{ }^{\mathrm{k}}, \ldots, \mathrm{x}_{\mathrm{n}}{ }^{\mathrm{k}}, \ldots \mathrm{x}_{1}{ }^{\mathrm{m}}, \ldots, \mathrm{x}_{\mathrm{n}}{ }^{\mathrm{m}}\right) \in \mathbb{N}^{\mathrm{n} \times \mathrm{m}}$

which satisfy the condition:

$$
\forall_{\mathrm{i} \in\{1, \ldots, \mathrm{n}\}} \quad \sum_{\mathrm{k}=1}^{\mathrm{m}} \mathrm{x}_{\mathrm{i}}{ }^{\mathrm{k}}=\Omega_{\mathrm{i}}
$$


Feasible allocations describe the ways of distribution of goods among the consumers and they will be written down also as $\left(x_{i}^{k}: i=1, . ., n ; k=1, \ldots, m\right)$.

The components $\mathrm{x}_{1}{ }^{\mathrm{k}}, \ldots, \mathrm{x}_{\mathrm{n}}{ }^{\mathrm{k}}$ denote values of proper goods which are assigned to the $\mathrm{k}^{\text {th }}$ consumer. For example, $\mathrm{x}_{2}{ }^{5}$ means the number of the second commodity assigned to the fifth consumer.

$\mathrm{A}-$ the set of all feasible allocations.

Each feasible allocation $\mathrm{x}=\left(\mathrm{x}_{1}{ }^{1}, \ldots, \mathrm{x}_{\mathrm{n}}{ }^{1}, \ldots, \mathrm{x}_{1}{ }^{\mathrm{k}}, \ldots\right.$, $\left.\mathrm{x}_{\mathrm{n}}{ }^{\mathrm{k}}, \ldots . . \mathrm{x}_{1}{ }^{\mathrm{m}}, \ldots, \mathrm{x}_{\mathrm{n}}{ }^{\mathrm{m}}\right)$ is connected with the vector $\mathrm{u}(\mathrm{x})$ :

$$
\mathrm{u}(\mathrm{x})=\left(\mathrm{u}_{1}\left(\mathrm{x}_{1}{ }^{1}, \ldots, \mathrm{x}_{\mathrm{n}}{ }^{1}\right), \ldots, \mathrm{u}_{\mathrm{m}}\left(\mathrm{x}_{1}{ }^{\mathrm{m}}, \ldots, \mathrm{x}_{\mathrm{n}}{ }^{\mathrm{m}}\right)\right)
$$

Vector $u(x)$ gives the values of the utility function of all consumers.

Pareto Optimal allocations are the vectors

$$
\mathrm{y}=\left(\mathrm{y}_{1}{ }^{1}, \ldots, \mathrm{y}_{\mathrm{n}}{ }^{1}, \ldots ., \mathrm{y}_{1}{ }^{\mathrm{m}}, \ldots, \mathrm{y}_{\mathrm{n}}{ }^{\mathrm{m}}\right) \in \mathrm{A}
$$

which satisfy the following condition:

$$
\mathrm{u}(\mathrm{y}) \in \mathrm{ND}\{\mathrm{u}(\mathrm{x}): \mathrm{x} \in \mathrm{A}\}
$$

\section{A. Numerical example}

The following numerical example is taken from work by Sitarz [1]. We consider a model with the following data:

- there are 3 consumers on the market, i.e. $\mathrm{m}=3$,

- there are 3 commodities to distribute, i.e. $n=3$,

- there are 2 of each commodity, i.e. $\Omega_{1}=\Omega_{2}=\Omega_{3}=2$.

The utility functions of the particular consumers have the form:

- $\mathrm{u}_{1}\left(\mathrm{x}_{1}, \mathrm{x}_{2}, \mathrm{x}_{3}\right)=\mathrm{x}_{1}+2 \mathrm{x}_{2}+3 \mathrm{x}_{3}$

- $\mathrm{u}_{2}\left(\mathrm{x}_{1}, \mathrm{x}_{2}, \mathrm{x}_{3}\right)=\mathrm{x}_{1} \cdot \mathrm{x}_{2} \cdot \mathrm{x}_{3}$

- $\mathrm{u}_{3}\left(\mathrm{x}_{1}, \mathrm{x}_{2}, \mathrm{x}_{3}\right)=3 \mathrm{x}_{1}+\mathrm{x}_{2}+\mathrm{x}_{3}$

\section{B. Construction of the process}

We have 6 periods:

$$
\mathrm{T}=\mathrm{n} \cdot(\mathrm{m}-1)=3 \cdot 2=6
$$

$\underline{\text { Feasible states }}$

$$
\mathrm{S}_{1}=\mathrm{s}
$$

We find the remaining feasible states by using the formula:

$$
\mathrm{S}_{\mathrm{t}}=\left\{0,1, \ldots, \Omega_{\lfloor(\mathrm{t}-2):(\mathrm{m}-1)\rfloor+1}\right\} .
$$

Thus

$$
\mathrm{S}_{2}=\mathrm{S}_{3}=\Omega_{1}=2 \text {. }
$$

$$
\begin{aligned}
& S_{4}=S_{5}=\Omega_{2}=2 . \\
& S_{6}=S_{7}=\Omega_{3}=2 .
\end{aligned}
$$

Feasible decisions

for $\mathrm{t} \in\{1,3,5\}$ and $\mathrm{s}_{\mathrm{t}} \in \mathrm{S}_{\mathrm{t}}$

$$
D_{t}\left(s_{t}\right)=S_{t+1}=\{0,1,2\} \text {. }
$$

for $\mathrm{t} \in\{2,4,6\}$

$$
D_{t}(0)=\{0\}, D_{t}(0)=\{0,1\}, D_{t}(0)=\{0,1,2\}
$$

\section{Values of the period criteria function}

- Case $I$, for $\mathrm{t} \in\{2,4,6\}$

Table 2 shows the values of the stage criteria functions in this case.

- Case II, for $t \in\{1,3,5\}$

Table 3 shows the values of the stage criteria function in this case.

The graph of the described multi-period decision process is shown in figure 1 , we have given only the chosen values of the criteria function, whereas we have given all feasible states and decisions

\section{Pareto-optimal allocations}

Now, we will generate Pareto Optimal allocations. We will find them by solving the DP problem (figure 2). We will use the algorithm from subsection II.C. The calculations are illustrated in table 4. Simultaneously, together with the values obtained in the last row of table 4, we obtain 16 Pareto Optimal allocations. Below, all maximal values of the utility function, together with the relevant allocations are presented in table 5 .

\section{E. Compromise hypersphere method}

We will conduct the method described in section III.

Step 1. Pareto Optimal allocations mean the efficient realizations of the considered dynamic process. Thus, the efficient realizations (obtained earlier in subsection 4.3) have the following notation: $r^{1}, r^{2}, \ldots, r^{16}$.

Step 2. Decision maker chooses the parameter $q$ as the representation of his risk aversion following the rule: The greater risk aversion the greater $q$. In this case we consider $q=2$.

The optimal values of the objective function of the problem (13) are as follows:

$$
\overline{\min }(13)^{2}=0.473
$$

Step 3. On the basis of the distance to the previously found hypersphere we obtain ranking presented in table 6. 
Table 2. Values of the period criteria function $w$ for $t \in\{2,4,6\}$.

\begin{tabular}{|c|c|c|c|c|}
\hline \multicolumn{2}{|c|}{$\mathrm{f}_{\mathrm{t}}\left(\mathrm{s}_{\mathrm{t}}, \mathrm{s}_{\mathrm{t}+1}\right)$} & \multicolumn{3}{|c|}{$\mathrm{t}$} \\
\cline { 2 - 5 } & $(2,2)$ & 2 & 4 & 6 \\
\hline \multirow{4}{*}{$\left(\mathrm{s}_{\mathrm{t}}, \mathrm{s}_{\mathrm{t}+1}\right)$} & $(2,1)$ & $(0,0,6)$ & $(0,0,2)$ & $(0,0,2)$ \\
\cline { 2 - 5 } & $(2,0)$ & $(0,2,0)$ & $(0,1,1)$ & $(0,1,1)$ \\
\cline { 2 - 5 } & $(1,1)$ & $(0,0,3)$ & $(0,2,0)$ & $(0,2,0)$ \\
\cline { 2 - 5 } & $(1,0)$ & $(0,1,0)$ & $(0,0,1)$ & $(0,0,1)$ \\
\cline { 2 - 5 } & $(0,0)$ & $(0,0,0)$ & $(0,1,0)$ & $(0,1,0)$ \\
\hline
\end{tabular}

Table 3. Values of the period criteria function $\mathrm{w}$ for $\mathrm{t} \in\{1,3,5\}$.

\begin{tabular}{|c|c|c|c|c|}
\hline \multirow{2}{*}{\multicolumn{2}{|c|}{$\mathrm{f}_{\mathrm{t}}\left(\mathrm{s}_{\mathrm{t}}, \mathrm{s}_{\mathrm{t}+1}\right)$}} & \multicolumn{3}{|c|}{$\mathrm{t}$} \\
\hline & & \multirow{2}{*}{$\frac{1}{(0,1,0)}$} & \multirow{2}{*}{3} & \multirow{2}{*}{5} \\
\hline \multirow{12}{*}{$\left(\mathrm{s}_{\mathrm{t}}, \mathrm{s}_{\mathrm{t}+1}\right)$} & $(\mathrm{s}, 2)$ & & & \\
\hline & $(\mathrm{s}, 1)$ & $(1,1,0)$ & - & - \\
\hline & $(\mathrm{s}, 0)$ & $(2,1,0)$ & - & - \\
\hline & $(2,2)$ & - & $(0,1,0)$ & $(0,1,0)$ \\
\hline & $(2,1)$ & - & $(2,1,0)$ & $(3,1,0)$ \\
\hline & $(2,0)$ & - & $(4,1,0)$ & $(6,1,0)$ \\
\hline & $(1,2)$ & - & $(0,1,0)$ & $(0,1,0)$ \\
\hline & $(1,1)$ & - & $(2,1,0)$ & $(3,1,0)$ \\
\hline & $(1,0)$ & - & $(4,1,0)$ & $(6,1,0)$ \\
\hline & $(0,2)$ & - & $(0,1,0)$ & $(0,1,0)$ \\
\hline & $(0,1)$ & - & $(2,1,0)$ & $(3,1,0)$ \\
\hline & $(0,0)$ & - & $(4,1,0)$ & $(6,1,0)$ \\
\hline
\end{tabular}

Table 4. Calculations obtained with the help of the algorithm from subsection 2.3.

\begin{tabular}{|c|c|c|c|}
\hline $\mathrm{t}$ & $\mathrm{ND}\left\{\mathrm{F}_{\mathrm{t}} \rightarrow\left(\mathrm{R}_{\mathrm{t}} \rightarrow(0)\right\}\right.$ & $\mathrm{ND}\left\{\mathrm{F}_{\mathrm{t}} \rightarrow\left(\mathrm{R}_{\mathrm{t}} \rightarrow(1)\right\}\right.$ & $\mathrm{ND}\left\{\mathrm{F}_{\mathrm{t}} \rightarrow\left(\mathrm{R}_{\mathrm{t}} \rightarrow(2)\right\}\right.$ \\
\hline 1 & $(2,1,0)$ & $\begin{array}{l}(1,1,0) \\
\end{array}$ & $\begin{array}{l}(0,1,0) \\
\end{array}$ \\
\hline 2 & $(2,0,0),(1,1,0),(0,2,0)$ & $(1,0,3),(0,1,3)$ & $(0,0,6)$ \\
\hline 3 & $\begin{array}{l}(6,0,0),(5,1,0),(4,2,0), \\
(5,0,3),(4,1,3),(4,0,6)\end{array}$ & $\begin{array}{r}(4,0,0),(3,1,0),(2,2,0) \\
(3,0,3),(2,1,3),(2,0,6)\end{array}$ & $\begin{array}{l}(2,0,0),(1,1,0),(0,2,0), \\
(1,0,3),(0,1,3),(0,0,6)\end{array}$ \\
\hline 4 & $\begin{array}{c}(6,0,0),(5,0,3),(4,0,6),(3,1,0),(2,2,0)(2,1,3) \\
(1,2,0),(0,4,0)(0,2,3)\end{array}$ & $\begin{array}{l}(4,0,1),(3,0,4),(2,0,7) \\
(1,1,1),(0,2,1)(0,1,4),\end{array}$ & $\begin{array}{l}(2,0,2),(1,0,5) \\
(0,1,5),(0,0,8)\end{array}$ \\
\hline 5 & $\begin{array}{l}(12,0,0),(11,0,3),(10,0,6),(9,1,0),(8,2,0)(8,1,3) \\
(7,2,0),(6,4,0)(6,2,3),(8,0,7),(6,1,5),(6,0,8)\end{array}$ & $\begin{array}{l}(9,0,0),(8,0,3),(7,0,6),(6,1,0), \\
(5,2,0),(5,1,3),(4,2,0),(3,4,0) \\
(3,2,3),(5,0,7)(3,1,5),(3,0,8)\end{array}$ & $\begin{array}{l}(6,0,0),(5,0,3),(4,0,6),(3,1,0), \\
(2,2,0)(2,1,3),(1,2,0),(0,4,0) \\
(0,2,3),(2,0,7),(0,1,5),(0,0,8)\end{array}$ \\
\hline 6 & $\begin{array}{c}(12,0,0),(11,0,3),(10,0,6),(8,0,7),(6,0,8),(6,1 \\
0),(5,2,0)(5,1,3),(3,4,0)(3,2,3),(3,1,5) \\
(0,8,0),(0,4,3),(0,0,8),(0,2,4),\end{array}$ & $\begin{array}{l}(9,0,1),(8,0,4),(7,0,7) \\
\quad(5,0,8),(3,0,9)\end{array}$ & $\begin{array}{l}(6,0,2),(5,0,5),(4,0,8) \\
(2,0,9),(0,0,10)\end{array}$ \\
\hline & \multicolumn{3}{|c|}{$\begin{array}{c}(12,0,0),(11,0,3),(10,0,6),(8,0,7),(6,0,8),(6,1,0),(5,2,0),(5,1,3),(3,4,0)(3,2,3),(3,1,5),(0,8,0)(0,4,3), \\
(0,2,4),(3,0,9),(0,0,10)\end{array}$} \\
\hline
\end{tabular}

Table 5. Values of the utility function, together with the relevant Pareto Optimal allocations.

\begin{tabular}{|c|c|}
\hline$\left(\mathbf{u}_{\mathbf{1}}, \mathbf{u}_{\mathbf{2}}, \mathbf{u}_{\mathbf{3}}\right)$ & Pareto optimal allocation \\
\hline$(12,0,0)$ & $\mathrm{r}^{1}=(2,2,2,0,0,0,0,0,0)$ \\
\hline$(11,0,3)$ & $\mathrm{r}^{2}=(1,2,2,0,0,0,1,0,0)$ \\
\hline$(10,0,6)$ & $\mathrm{r}^{3}=(0,2,2,0,0,0,2,0,0)$ \\
\hline$(8,0,7)$ & $\mathrm{r}^{4}=(0,1,2,0,0,0,2,1,0)$ \\
\hline$(6,0,8)$ & $\mathrm{r}^{5}=(0,0,2,0,0,0,2,2,0)$ \\
\hline$(6,1,0)$ & $\mathrm{r}^{6}=(1,1,1,1,1,1,0,0,0)$ \\
\hline$(5,2,0)$ & $\mathrm{r}^{7}=(0,1,1,2,1,1,0,0,0)$ \\
\hline$(5,1,3)$ & $\mathrm{r}^{8}=(0,1,1,1,1,1,1,0,0)$ \\
\hline
\end{tabular}

\begin{tabular}{|c|c|}
\hline$\left(\mathbf{u}_{\mathbf{1}}, \mathbf{u}_{\mathbf{2}}, \mathbf{u}_{\mathbf{3}}\right)$ & Pareto optimal allocation \\
\hline$(3,4,0)$ & $\mathrm{r}^{9}=(0,0,1,2,2,1,0,0,0)$ \\
\hline$(3,2,3)$ & $\mathrm{r}^{10}=(0,0,1,1,2,1,1,0,0)$ \\
\hline$(3,1,5)$ & $\mathrm{r}^{11}=(0,1,1,1,1,1,1,0,0)$ \\
\hline$(0,8,0)$ & $\mathrm{r}^{12}=(0,0,0,2,2,2,0,0,0)$ \\
\hline$(0,4,3)$ & $\mathrm{r}^{13}=(0,0,0,1,1,2,1,0,0)$ \\
\hline$(0,2,4)$ & $\mathrm{r}^{14}=(0,0,0,1,1,2,1,1,0)$ \\
\hline$(3,0,9)$ & $\mathrm{r}^{15}=(0,0,1,0,0,0,2,2,1)$ \\
\hline$(0,0,10)$ & $\mathrm{r}^{16}=(0,2,2,0,0,0,2,2,2)$ \\
\hline
\end{tabular}




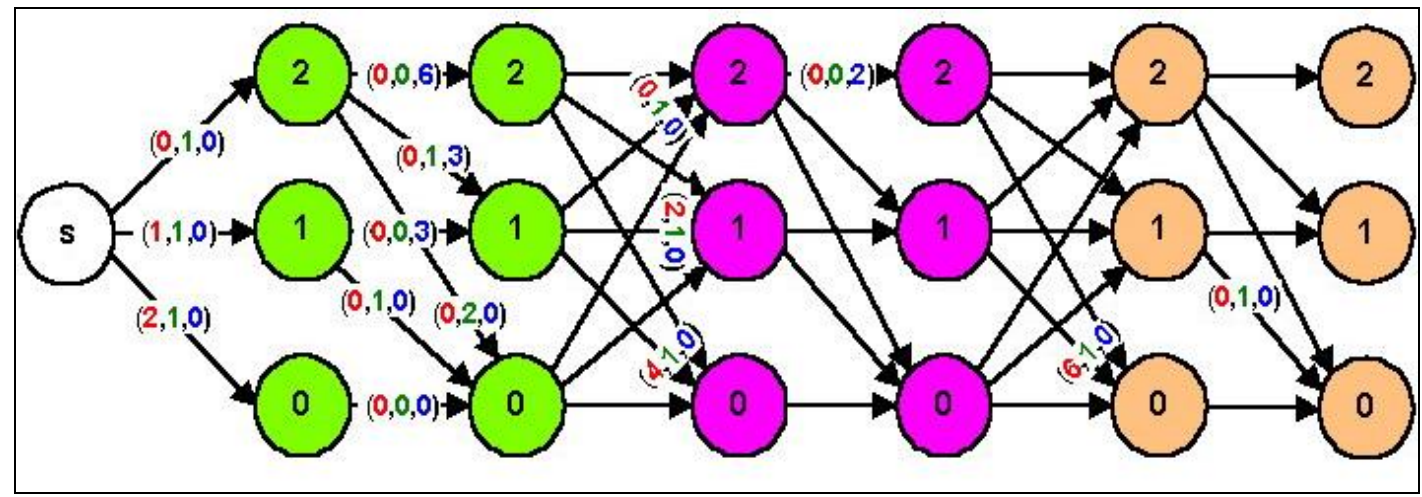

Fig. 1. The graph of the decision process with chosen values of period criteria functions.

Table 6: Ranking obtained by using compromise hypersphere method

\begin{tabular}{|l|l|}
\hline $1 . r^{7}$ & $9 \cdot r^{5}$ \\
2. $r^{2}$ & $10 \cdot r^{10}$ \\
3. $r^{11}$ & $11 \cdot r^{16}$ \\
4. $r^{13}$ & $12 \cdot r^{6}$ \\
$5 . r^{1}$ & $13 \cdot r^{15}$ \\
$6 . r^{3}$ & $14 \cdot r^{9}$ \\
7. $r^{8}$ & $15 \cdot r^{4}$ \\
8. $r^{14}$ & $16 \cdot r^{12}$ \\
\hline
\end{tabular}

\section{SUMMARY}

We considered a multi-criteria dynamic process with a finite number of periods, states and decision variables. To obtain the efficient realizations, we used the forward algorithm presented in subsection II.C. Next step was to rank the obtained efficient realizations, which was made by using the compromise hypersphere method described in section III. Such general approach allowed us to apply the presented model to many multi-period, multi-criteria decision making problems. The exemplary area of applications of the presented dynamic model was the market model described by Elkeland [8]. We used the market model to illustrate the application of the presented theory. Further research and problems to solve are as follows:

- Using other structures to describe the preferences of decision maker: interval coefficients, fuzzy numbers or stochastic orders,

- Introducing interactive version of the compromise hypersphere method,

- Comparison with other methods based on compromise programming, for example with methods from work by Opricovic and Tzeng [14].

- Applying the sensitivity analysis of the obtained ranking, [15].

\section{ACKNOWLEDGMENT}

This project was financed with means of the National Science Centre (Poland) according to decision number DEC-2013/11/B/HS4/01471.

\section{REFERENCES}

[1] Sitarz S., "Pareto Optimal Allocations and Dynamic Programming", Annals of Operations Research, 172/1, 203-219, 2009.

[2] Sitarz S., "Dynamic Programming with Ordered Structures: Theory, Examples and Applications", Fuzzy Sets and Systems, 161, 2623-2641, 2010.

[3] Bazgan C, Hugot H., Vanderpooten D., "Solving efficiently the $0-1$ multi-objective knapsack problem", Computers and Operations Research, 36, 260-279, 2009.

[4] Sitarz S., "Multiple Criteria Dynamic Programming and Multiple Knapsack Problem", Applied Mathematics and Computation, 228, 598-605, 2014.

[5] Woerner S., Laumanns R., Fertis A., "Approximate dynamic programming for stochastic linear control problems on compact state spaces", European Journal of Operational Research, 241, 85-98, 2015.

[6] Gass S. I., Roy P. G., "The compromise hypersphere for multiobjective linear programming", European Journal of Operational Research 144, 459-479, 2003.

[7] Charnes A., Cooper W. W., "Goal Programming and Mulitple Objective Optimiaztion", European Journal of Operation Research, 1, 39-45, 1957.

[8] Zeleny M., "Multiple Criteria Decision Making", McGraw-Hill Book Company, New York, 1982.

[9] Trzaskalik T., Sitarz S., "Discrete dynamic programming with outcomes in random variable structures", European Journal of Operational Research, 177/3, 1535-1548, 2007.

[10] Sitarz S., "Hybrid methods in multi-criteria dynamic programming", Applied Mathematics and Computation, 180/1, 38-45, 2006.

[11] Sitarz S., "Discrete dynamic programming in ordered structures and its applications". Ph. D., University of Lodz, Poland, (in polish), 2003.

[12] Ballestero E., "Selecting the CP metric: A risk aversion approach", European Journal of Operational Research, 97, 593-596, 1996.

[13] Ekeland I., "Elements d'economic mathematic", Hermann, Paris, 1979.

[14] Opricovic S., Tzeng G.H., "Compromise solution by MCDM methods: A comparative analysis of VIKOR and TOPSIS", European Journal of Operational Research, 156, 445-455, 2004.

[15] Sitarz S., "Approaches to sensitivity analysis in MOLP", International Journal of Information Technology and Computer Science, 6 (3), 54-60, 2014. 


\section{Authors' Profiles}

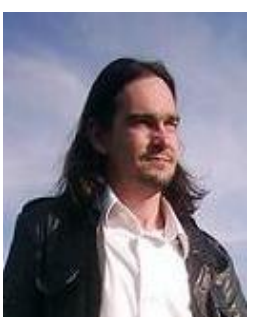

Sebastian Sitarz was born on March 19, 1975. He received his MS in Mathematics from University of Silesia (Poland) in 1999; PhD in Economics from University of Lodz in 2003 (Poland). Currently, he is working as a Lecturer in the Institute of Mathematics, the University of Silesia, Katowice (Poland), since 2003. His research areas include multi-objective linear programming, dynamic programming and their applications. His papers appeared in European Journal of Operational Research, Fuzzy Sets and Systems, Computers and Operations Research, Annals of Operations Research, Applied Mathematics and Computation, Asia Pacific Journal of Operational Research and others.

How to cite this paper: Sebastian Sitarz,"Compromise Hypersphere for Multi-Criteria Dynamic Programming", IJIEEB, vol.7, no.1, pp.1-7, 2015. DOI: 10.5815/ijieeb.2015.01.01 